EDITORIAL

\title{
Sobre ensinar ciências, investigação e nosso papel na sociedade
}

\author{
Lúcia Helena Sasseron ${ }^{1}$ \\ https://orcid.org/0000-0001-5657-9590
}

\section{Para quê ensinar ciências?}

A pergunta que inicia este texto é, aparentemente, simples: Para quê ensinar ciências?

Muitos já fizeram este questionamento, muitas respostas já foram oferecidas, e, embora isso, a simplicidade em sua estrutura não corresponde à construção de uma resposta simples, consensual e definitiva.

Antes de me aventurar a responder à pergunta inicial, trago o exemplo a seguir como forma de construir minha argumentação. Para tanto, recorro a algo a qual nos habituamos nos dias atuais: o acesso direto e rápido à informação relacionada a uma dúvida.

Ao inserir no Google, buscador online muito utilizado em nosso dia a dia, a pergunta que abre este texto, obtém-se mais de 14 milhões de respostas. Surgem referências diretas a sites em que a própria pergunta é respondida, assim como também menção a derivações da questão original: por que ensinar ciências? e o que ensinar em ciências?, ou a ideias afins: o que é a disciplina de ciências?, para quê serve a ciência? e, qual a importância do ensino de ciências? Em cada um destes links encontramos textos com linguagem coloquial provenientes de blogs, textos de divulgação em revistas de larga circulação, artigos científicos publicados em periódicos especializados, vídeos caseiros e opinativos e mesmo vídeo-aulas. Uma amplitude de respostas e de modos de responder à pergunta.

Embora seja fascinante estarmos frente a tão grande variedade de ideias, interessame pensar na qualidade da resposta obtida pela pesquisa. Entendo que seu dimensionamento esteja relacionado à análise das diferentes respostas na relação direta com a pergunta e com as premissas (explícitas ou implícitas) que fundamentam a própria busca.

Para o caso desta busca (assim como para muitos outros), diante de mais de 14 milhões de devolutivas a uma pergunta, pode ser demasiada longa e exaustiva a avaliação atenta de todas, o que implica na necessidade de encontrar mecanismos para esta análise.

Neste processo, algumas considerações são feitas (mesmo que de modo inconsciente), estando elas associadas a elementos que condicionam o tipo de resposta que se pretende obter, podendo representar desde a disponibilidade de tempo que o sujeito apresenta para alcançar uma resposta, passando pelos diferentes níveis de complexidade que se tem ou que se pretende

\footnotetext{
${ }^{1}$ Universidade de São Paulo (USP), Faculdade de Educação, Departamento de Metodologia do Ensino e

Educação Comparada, São Paulo, SP, Brasil. E-mail: sasseron@usp.br
} 
atingir, e até mesmo pelas relações entre as perspectivas originais para a pesquisa e as expectativas com as respostas. O que aglutina cada uma destas possibilidades (e muitas outras existentes e não listadas) é a capacidade de construção de posicionamento sobre as informações encontradas.

Este posicionamento pode representar tanto a anulação de perspectivas pessoais, pela aceitação irrestrita e irrefletida das informações obtidas, quanto a congregação entre perspectivas já existentes e as novas apresentadas, evidenciando uma amálgama entre ideias, podendo também ocorrer de o posicionamento revelar o abandono de uma perspectiva anterior para aceitação de um novo paradigma a partir da reflexão possibilitada pelas novidades advindas da exploração.

Não defendo que estas três possibilidades sejam as únicas possíveis, pois considero haver nuances entre cada um destes três cenários extremos, desvelando tons e matizes diversos que representem o posicionamento consolidado. Mas já destaco que aquela primeira opção, a aceitação irrefletida, é aquela a que mais me oponho como educadora.

Diante desta construção (feita no intuito de uma meta análise), e dos conhecimentos e das experiências que trago comigo até este momento, arrisco-me a responder à pergunta Para quê ensinar ciências? Para mim, ensinar ciências pode significar, nos dias atuais, a conferência de oportunidades para que os estudantes sejam apresentados a modos de realizar buscas sobre questões que os aflijam e, a partir das informações a sua disposição, construir seu posicionamento frente à dúvida.

Isso pode parecer simples, ou até desprovido de sentido, caso a ideia sobre realizar buscas seja concebida como ação mecânica, irrefletida. Por isso, é importante discutir como concedo tal atividade: entendo que, antes mesmo de realizar uma busca, há uma causa que a propulsiona. Demandas externas ou internas geram questionamento por meio do qual tem início o processo. Questões cujas respostas são únicas, tendem a não demandar tempo para sua resposta. Mas boas questões não costumam ser assim, não têm resposta única, e isso que pode acarretar um longo processo de busca por informações, de análise de resultados, de novas buscas e novas análises até chegar a uma possível resposta diante da pergunta inicial.

Todo este processo é uma investigação. Se relacionada ao mundo natural, esta investigação certamente vincula-se às ciências da natureza.

Assim, minha opinião é a de que, ao ensinar ciências nos dias atuais, devemos nos afastar de questões simples, cujas respostas podem ser obtidas de modo direto pela pesquisa em buscadores online. Isso porque esta modalidade de ação pouco contribui para a formação dos estudantes, uma vez que pode estar vinculada a movimentos automáticos, em que a análise e a construção de modos de atuar não são afloradas. Além disso, é preciso considerar que a grande maioria dos estudantes já chega às escolas habituados (ou ao menos cientes) de mecanismos de buscas para respostas a questões simples.

Se a escola tem como objetivo oportunizar aos estudantes acesso a informações e modos de construir posicionamento aos quais não teriam possibilidade de se envolver em outras situações (YOUNG, 2007), uma das contribuições que o ensino de ciências pode trazer vincula-se ao seu próprio modo de construir conhecimento. Não porque seja melhor do que outros (embora eu o considere), mas porque a construção de entendimentos nas ciências envolve não apenas a busca por informações, mas também porque envolve ações disciplinadas e criativas para realiza-la, aceita novas possibilidades, ainda que discordantes de ideias iniciais, aprecia a análise crítica sempre mantendo pressupostos bem firmados. É uma forma sistêmica, mas não mecânica, de relação com informações, permitindo e dependendo da ação intelectual para análise do que já se sabe para o que está em construção.

Diante disso, é preciso avançar um pouco para a visão de ciência que sustenta essa minha posição. 


\section{Sobre a investigação das ciências como atividade social}

Compreender fenômenos corriqueiros, buscar respostas para o que é, como surge e como se desenvolve a vida, avaliar condições para o bem-estar, considerar elementos para a conservação da saúde são apenas alguns dos propulsores que levam pessoas a se embrenharem com ações de investigação que podem culminar com a proposição de novos conhecimentos.

Ao longo de reordenamentos de interesses e de reorientações de limites, condições e processos, na relação estreita entre o que já se sabe e o que se imagina ou sequer se possa imaginar (RHEINBERGER, 1997), constituem-se as ações das ciências.

Reconheço que o empreendimento em que se envolvem os cientistas seja objetivo, disciplinado e criativo; e, para alguns estudiosos das ciências, estas características surgem porque as ciências são uma atividade social (KNORR-CETINA, 1999; LONGINO, 1990; PICKERING, 1995).

Como atividade social, as ações que caracterizam as ciências são também sociais e, portanto, desenvolvê-las resulta na constituição de um contexto social em que práticas sociais são realizadas por um grupo. E aqueles reordenamentos e aquelas reorientações entre o que já se sabe e o que se pesquisa congregados a ações de investigação de novos fenômenos e situações, envolvem e revelam práticas epistêmicas que, pela própria natureza que as caracteriza, contribuem para o empreendimento das ciências tornarem-se objetivo, lógico, disciplinado e criativo.

A pesquisa em ensino de ciências prima por avaliar modos de ensinar as ciências para a formação do cidadão contemporâneo. Em uma perspectiva histórica, várias já foram e são as tentativas de tornar o ensino de ciências mais distante de uma abordagem ordenada e metódica de fatos. A partir da metade do século passado houve grande movimento para explorar atividades experimentais como uma forma de aproximar os estudantes de aspectos das ciências. Com ênfase conferida a processos descritivos para a orientação das ações, os procedimentos ganhavam destaque e havia expectativa de que os alunos "descobrissem" os conceitos, as leis ou os modelos que poderiam ser comprovados por estas atividades (OSBORNE, 2016). Nesta vertente, ora os procedimentos surgiam como o centro das atenções, ora os conceitos. Mais recentemente, os pesquisadores revelam atenção à crítica, essencial para o desenvolvimento dos conhecimentos científicos, como elemento central para o ensino das ciências (GRANDY; DUSCHL, 2007; HURD, 1998; LEMKE, 2006). Surge, portanto, a oportunidade para que práticas epistêmicas sejam exploradas, considerando que elas se caracterizam por serem maneiras de construir entendimento a partir e por meio da avaliação sobre o que se sabe.

Estas ideias fundamentam o claro movimento, nos dias atuais, entre pesquisadores da área, para que o ensino de ciências confira acesso a características da atividade científica (DUSCHL, 2008; STROUPE, 2014; WINDSCHTIL; THOMPSON; BRAATEN, 2018), seja de maneira explícita, pela realização de ações em que estejam identificadas práticas executadas nas ciências, seja de maneira implícita, pelo contato com estas práticas ainda que não seja diretamente mencionado a sua utilização por cientistas.

Nesta perspectiva, além da dimensão conceitual, as dimensões social e epistêmica dos conhecimentos são trazidas para o centro do processo didático na tentativa de que aspectos de domínio geral das ciências estejam presentes em aula (DUSCHL, 2008; STROUPE, 2014). Para tanto, e na relação com as perspectivas sobre a atividade científica já mencionadas, torna-se imprescindível que a autoridade cognitiva seja distribuída em sala de aula; o que não sugere que o professor deixa de ser responsável pelas ações didático-pedagógicas, mas sim que as ações para a aprendizagem deixam de ser trabalhadas como empreendimentos privado e, por isso, unitários e individuais, e passam a ser concebidas e realizadas como empreendimento público 
e, portanto, social (STROUPE, 2014). Abre-se, pois, a possibilidade para o diálogo, para a exposição de ideias e, com isso, para o desenvolvimento de respeito pelo pensamento divergente.

Neste processo, as práticas epistêmicas das ciências tornam-se o meio pelo qual o envolvimento dos estudantes com a investigação de fenômenos possibilita a aprendizagem sobre ciências (JIMÉNEZ-ALEIXANDRE; CRUJEIRAS, 2017; SASSERON, 2018), pois elas não são transmitidas ou meramente executadas: as práticas epistêmicas são acessadas e desenvolvidas pela e na interação, em contextos, a partir deles e devido aos objetivos construídos, sendo resultado e consequência de ações realizadas para propor e avaliar ideias sobre situações.

Desenvolver práticas epistêmicas em sala de aula de ciências permite o envolvimento dos estudantes com características das ciências e leva à dissociação da perspectiva enciclopédica de ciências, em que os fatos são mencionados a partir de uma única visão, em que se sugere que os processos para sua obtenção ou proposição não são merecedores de atenção, sendo apagados pela inexistência de menção. Permite a percepção do papel dos dados e das informações para a pesquisa científica, mesmo quando estes não coadunam com a realidade que gostaríamos de vislumbrar. Permite a análise destes dados e destas informações para identificação de evidências e o uso destas como justificativas e fundamento para ideias e posicionamentos em construção.

Desenvolver práticas epistêmicas em aulas de ciências permite que os estudantes dos dias atuais possam estar menos propensos a aceitar as falsas notícias, travestidas de verdades absolutas e, por isso, vendidas como irrefutáveis. Isso empodera os sujeitos para a vivência em uma sociedade que ainda aprende a conviver com a profusão de informações e com a abundância de opiniões pautadas apenas em observações de contato próximo, porque se fundamenta na necessidade de consideração de perspectivas menos egocêntricas e, portanto, mais amplas e complexas.

Ainda que eu esteja certa de que apenas as aulas de ciências não são suficientes para a formação dos sujeitos, talvez seja este papel que caiba a nós, educadores e pesquisadores das ciências: encontrar maneiras de oferecer aos demais cidadãos a oportunidade de viverem em sociedade de modo consciente, crítico e solidário. Porque este me parece ser um caminho essencial para construção de uma sociedade mais democrática e justa.

\section{Referências}

DUSCHL, R. A. Science education in three-part harmony: balancing conceptual, epistemic and social learning goals. Review of Research in Education, Thousand Oaks. v. 32, n. 1, p. 268-291, 2008. DOI: https://doi.org/10.3102/0091732X07309371.

GRANDY, R. E.; DUSCHL, R. A. Reconsidering the character and role of inquiry in school science: analysis of a conference. Science \& Education, Dordrecht, v. 16, n. 2, p. 141-166, 2007. DOI: https://doi.org/10.1007/s11191-005-2865-z.

HURD, P. D. Scientific literacy: new minds for a changing world. Science Education, Hoboken, v. 82, n. 3, p. 407-416, 1998. DOI: https://doi.org/10.1002/(SICI)1098237X(199806)82:3<407::AID-SCE6>3.0.CO;2-G.

JIMÉNEZ-ALEIXANDRE, M. P.; CRUJEIRAS, B. Epistemic practices and scientific practices in science education. In: TABER, K.; AKPAN, B. (ed.). Science education: an international course companion. Rotterdam: Sense Publishers, 2017. p. 69-80. 
KNORR-CETINA, K. Epistemic cultures: how the sciences make knowledge. Cambridge, MA: Harvard University Press, 1999.

LEMKE, J. L. Investigar para el futuro de la educación científica: nuevas formas de aprender, nuevas formas de vivir. Enseñanza de las Ciencias, Barcelona, v. 24, n. 1, p. 5-12, 2006.

LONGINO, H. E. Science as social knowledge: values and objectivity in science inquiry. Princeton: Princeton University Press, 1990.

PICKERING, A. The mangle of practice: time, agency and science. Chicago: University of Chicago Press, 1995.

OSBORNE, J. Defining a knowledge base for reasoning in science: the role of procedural and epistemic knowledge. In: DUSCHL, R. A.; BISMARCK, A. S. (ed.). Reconceptualizing STEM education: the central role of practices. New York: Routledge, 2016. p. 215-231.

RHEINBERGER, H. J. Toward a history of epistemic things: synthesizing proteins in the test tube. Redwood City: Stanford University Press, 1997.

SASSERON, L. H. Ensino de ciências por investigação e o desenvolvimento de práticas: uma mirada para a base nacional comum curricular. Revista Brasileira de Pesquisa em Educação em Ciências, Belo Horizonte, v. 18, p. 1061-1085, 2018. DOI: https://doi.org/10.28976/19842686 rbpec20181831061.

STROUPE, D. Examining classroom science practice communities: how teachers and students negotiate epistemic agency and learn science-as-practice. Science Education, Hoboken, v. 98, n. 3, p. 487-516, 2014. DOI: https://doi.org/10.1002/sce.21112.

WINDSCHITL, M.; THOMPSON, J.; BRAATEN, M. Ambitious science teaching, Boston: Harvard University Press, 2018.

YOUNG, M. Para que servem as escolas. Educação e Sociedade, Campinas, v. 28, n. 101, p. 1287-1302, 2007. DOI: http://dx.doi.org/10.1590/S0101-73302007000400002. 
